\title{
Practical Coulometric Detectors of Dissolved Oxygen
}

\author{
Ken NOZAKI*, Osamu HAMAMOTO ${ }^{\dagger}$, Shunich UCHIYAMA ${ }^{\dagger \dagger}$ and Hiroko KANEKO ${ }^{\dagger \dagger}$
}

Received January 16, 1998 ; Accepted February 19, 1998

\section{INTRODUCTION}

The measurement of dissolved oxygen (DO) is inevitable for monitoring the water quality of rivers, lakes and a greater part of water treatment facilities. Most of commercially available DO analyzers employ the methods of amperometry or potentiometry, such as a galvanic cell. However, the conventional electrochemical DO analysers still have some problems since the careful maintenance and calibrations within short period are needed to keep their reliability. Some laboratories, in practice, have begun to adopt redox potential measurements to control waste water treatment facilities in stead of the control by DO measurements. ${ }^{1}$ The DO analysers have been expected to be improved in these points.

Coulometric DO measurements give us novel means of solving the problems, since no calibration is needed, and high accurate and reliable monitoring can be expected. The coulometric technique can play an important role in a DO measuring field. In this note, we intend to demonstrate the two type of coulometric detectors; one is a rapid coulometric detector, the other is a flow cell type for continuous DO monitoring.

\section{EXPERIMENTAL}

The basic configuration of the coulometric detector was as described earlier. ${ }^{2}$. 31 In the DO detector, high purity nitrogen gas was introduced on the working electrode to isolate from the external atmosphere. The carbon fiber felt $38 \mathrm{~mm}$ diameter, $3 \mathrm{~mm}$ thickness) of the working electrode

Electrotechnical Laboratory (1-1-4 Umezono, Tsukuba 305-8568, Japan)

† Mitsui Engineering \& Shipbuilding CO., Ltd. (Tsukiji, Chuo-ku, Tokyo 104-8439 Japan)

${ }^{\dagger}$ Saitama Insititute of Technology (1690 Fusaiji, Okabe, Saitama 369-0293, Japan)

${ }^{+\dagger}{ }^{\dagger}$ Tsukuba Materials Information Laboratory Ltd. (3-23-4 Ninomiya, Tsukuba 305-0051, Japan) Key Words : Dissolved oxygen, Coulometry, Ionexchange membrane tubing, Carbon felt electrode

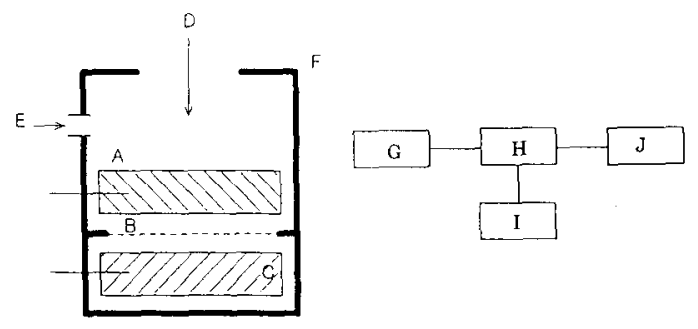

Fig. 1 DO detector configuration and block diagram of the experimental system.

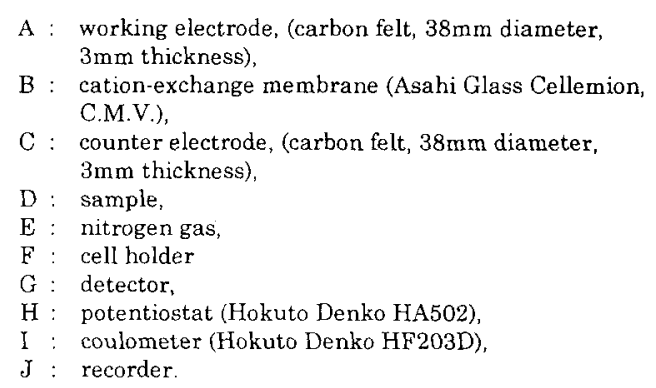

were coated with approximate $10 \mathrm{mg}$ of platinum by using a method of non-electrolytic plating method. The working and counter electrodes were impregnated in $0.5 \mathrm{M}$ sodium acetate-acetic acid solution ( $\mathrm{pH} 4.5$ ) containing $0.3 \mathrm{M}$ potassium hexaferrocyanide, and $0.5 \mathrm{~V}$ was applied between these two electrodes. In these conditions, the electrode reaction proceeds readily. ${ }^{23}$ The cross section of this detector and the experimental system are shown in Fig. 1.

Pure water was used as the sample for the DO determination. The concentrations of DO were adjusted by introducing high purity nitrogen gas and determined by Indigo Carmine method. ${ }^{4}$ ) The sample solutions were dropped into the center of working electrodes with a $50 \mu \ell$ or a $100 \mu \ell$ Eppendorf pipet after the residual current of detectors reached constant steady-state values.

In the next step, for the demonstration of continuous DO monitoring, a flow cell was also fabricated by using an ion-exchange membrane tube. The configuration of the flow cell is shown in Fig.2, and a piece of Nafion 117 tubing was 

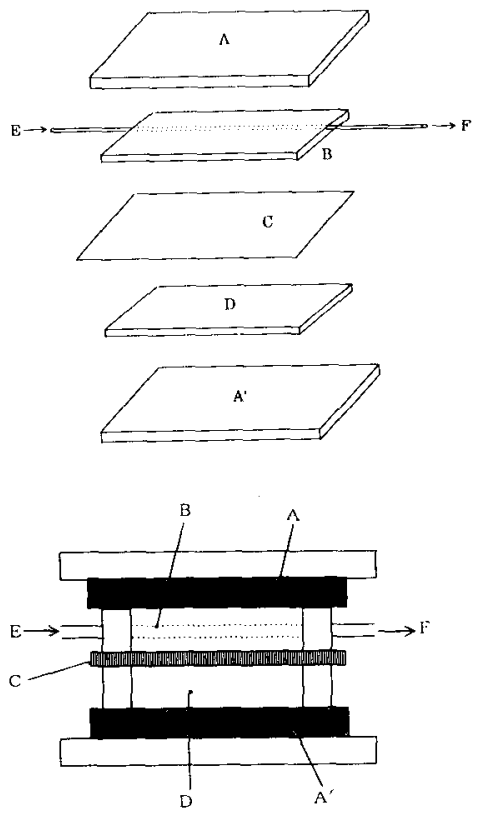

Fig.2 The structure of a flow coulometric DO detectors.

A, $A^{\prime}$ : carbon plates,

B: working electrode (carbon felt, $100 \mathrm{~mm}$ length, $10 \mathrm{~mm}$ width, $3 \mathrm{~mm}$ thickness),

C: cation exchange membrane,

D: counter electrode (carbon felt),

E: sample solution inlet,

F: sample solution outlet,

$\mathrm{G}$ : nafion 117 tubing,

$\mathrm{H}, \mathrm{H}^{\prime}$ : plastic plates,

I, I': silicon rubber gasket.

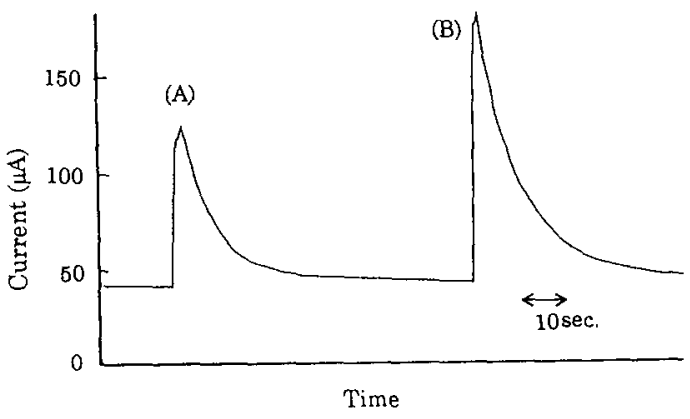

Fig.3(1) The current vs. time curves obtained for the determination of dissolved oxygen in pure water.

$\begin{array}{ll}\text { (A): } 50 \mu \ell \text { sample soln. } & \text { (B): } 100 \mu \ell \text { sample soln. }\end{array}$

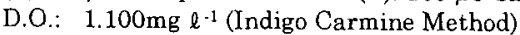

W.E.: $-0.5 \mathrm{~V}$ vs. C.E.

Electrolyte: $\quad 0.5 \mathrm{M} \mathrm{AcONa-AcOH}$ soln. containing

$27^{\circ} \mathrm{C}$

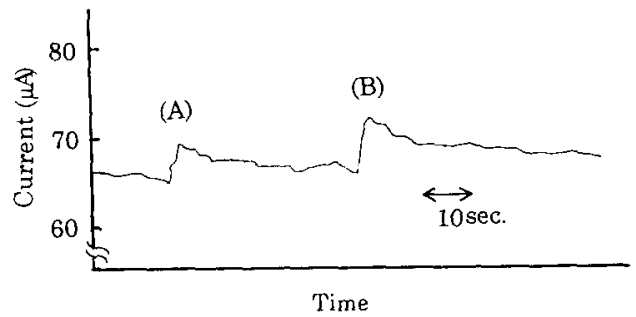

Fig.3(2) The current vs. time curves obtained for the determination of dissolved oxygen in pure water.

(A) $50 \mu \ell$ sample soln. $\quad$ (B) $100 \mu \ell$ sample soln.

D.O.: $0.030 \mathrm{mg}^{-1}$ (Indigo Carmine Method)

W.E.: $\rightarrow 0.5 \mathrm{~V}$ vs. C.E.

Electrolyte: $\quad 0.5 \mathrm{M}$ AcONa-AcOH soln. containing

$0.3 \mathrm{M}$ potassium hexaferrocyanide, $\mathrm{pH} 4.5$

$27^{\circ} \mathrm{C}$

employed for sampling the solutions. The coulometer was removed from the experimental system in this case.

\section{RESULT AND DISCUSSION}

In the cell shown in Fig. 1, current vs. time

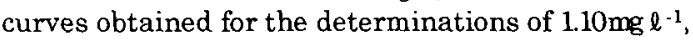
and $0.03 \mathrm{mg} \ell^{-1}$ of DO are shown in Fig. 3 .

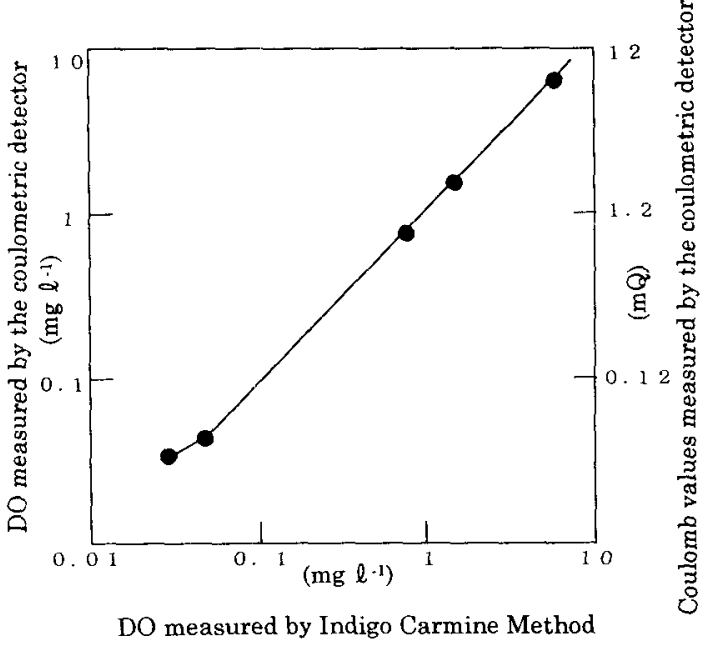

Fig.4 The relationship of DO determinations between the coulometry and the Indigo Carmine Method.

Sample : pure water,

Detector

Electrolyte : $0.5 \mathrm{MAcONa}-\mathrm{AcOH}$ soln. containing $0.3 \mathrm{M}$ potassium hexaferrocyanide, $\mathrm{pH} 4.5$,

W. E. : $-0.5 \mathrm{~V}$ vs. C. E.,

Sample volume : $100 \mu \ell$,

$27^{\circ} \mathrm{C}$. 


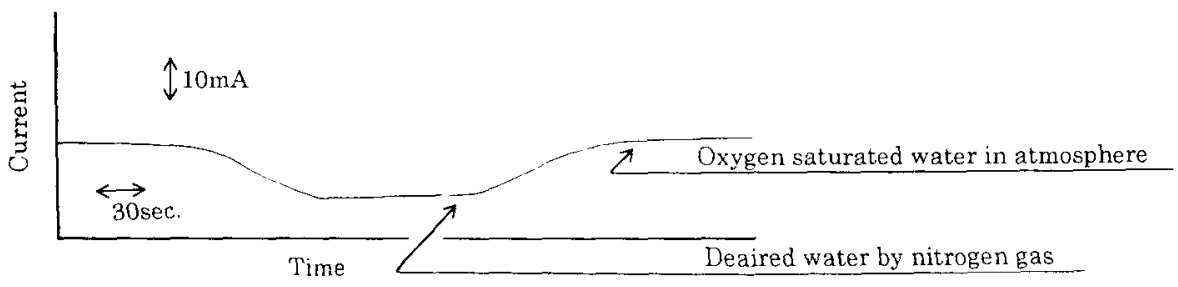

Fig.5 The current vs. time curve obtained by the flow coulometric DO detector

\author{
Sample : pure water, \\ Detector \\ W. E. : -0.5 V vs. C. E., \\ Sample flow rate: $5 \mathrm{~m} \mathrm{lmin}^{-1}$, \\ $25^{\circ} \mathrm{C}$.
}

Electrolyte : $0.5 \mathrm{MAcONa}-\mathrm{AcOH}$ soln. containing $0.3 \mathrm{M}$ potassium hexaferrocyanide, $\mathrm{pH} 4.5$,

Considering to the current-time curves for the 0.05 and $0.03 \mathrm{mg} \ell^{-1}$ determinations, the lower limit of this detector was found to be approximate $0.05 \mathrm{mg} \mathrm{\ell ^{-1 }}(50 \mathrm{ppb})$. The determination of $\mathrm{DO}$

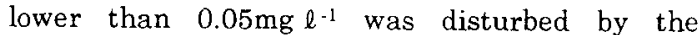
fluctuation of back-ground current due to the change of double layer capacitance when a sample solution was dropped to the working electrode surface. The electrolysis time was dependent on the concentration of DO, and within 50 seconds at most. Figure 4 shows the comparison between the coulometry and the Indigo Carmine method for the DO determination. This figure indicates that the results obtained by the coulometric detector are in fairly good agreement with those obtained by Indigo Carmine method.

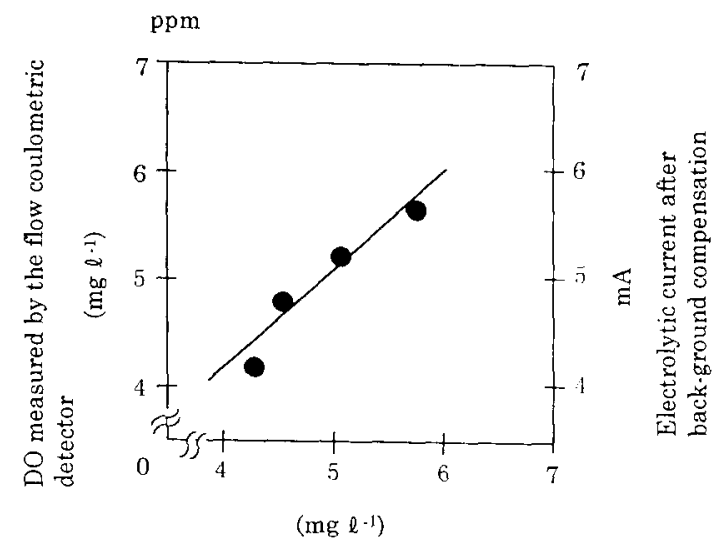

DO measured by a commercial galvanic cell

Fig. 6 The relationship of DO determinations between the flow coulometric detector and a commercial galvanic cell.

Sample : effluent of a waste water treatment facility, flow rate : $5 \mathrm{~m} \mathrm{\ell} \mathrm{min}^{-1}$,

DO meter : galvanic cell type, DKK-DO-31.
It is ordinary for automatic DO analyzers to be operated continuously, and can be anticipated to improve coulometric determinations of $\mathrm{DO}$ by introducing the flow cell technique using a ionexchange membrane tube. An typical current vs. time curve obtained by the flow coulometric cell is shown in Figure 5. The increasing and decreasing of current was proportional to the DO concentration of samples. The electrolytic current subtracted by back-ground level is related to the DO concentration as follows;

$$
I=\frac{2 F C L}{16 \times 60 \times 10^{3}}=0.20 C L,
$$

Where $I, C$ and $L$ are the current $(\mathrm{mA}), \mathrm{DO}$ concentration $\left(\mathrm{mg}^{-1}\right.$ ) and the sample flow rate $\left(\mathrm{m} \ell \min ^{-1}\right.$ ), respectively, and $F$ is Faraday constant. The above relationship was applicable to the region of below $7 \mathrm{~m} \ell \mathrm{min}^{-1}$ of the flow rate. Fig. 6 shows a relationship of DO determinations between the flow coulometric detector and a commercial galvanic cell. As shown in Fig.5 and Fig.6, the performance of flow coulometric detector become more stable and reliable by introducing an ion exchange membrane tubes.

This flow cell technique is expected to be available not only for DO determination but for components in liquid and gaseous samples.

\section{References}

1) M. Sakata, M. Kondo and S. Miki, The 34th Meeting of Sewage Engineering, Japan, 7-50, 530 (1997); B. Sun, Water Research, 31, 362 (1997); S. Takahashi, S. Kawabe and Y. Hase, The 29th Meeting of Sewage Engineering, Japan, 7-05, 305 (1991).

2) S. Uchiyama, M. Ono, S. Suzuki, and O. Hamamoto, Anal. Chem., 60 (17), 1835 (1988).

3) S. Uchiyama, S. Suzuki and O. Hamamoto, Electroanalysis, 1, 323, (1989).

4) Japan Industrial Standard K 0101-91(1991).

5) T. Takata and G. Muto, Anal. Chem., 45 (11) 1864 (1973). 